\title{
Klasifikasi Mamalia Berdasarkan Bentuk Wajah Dengan K-NN Menggunakan Fitur CAS Dan HOG
}

\author{
Muhammad Ezar Al Rivan*1, Yohannes ${ }^{2}$ \\ ${ }^{1,2}$ STMIK Global Informatika MDP; Jalan Rajawali No. 14, (0711) 376400 \\ ${ }^{1,2}$ Program Studi Teknik Informatika, STMIK Global Informatika MDP, Palembang \\ e-mail: *11 meedzhar@mdp.ac.id, ${ }^{2}$ yohannesmasterous@mdp.ac.id
}

\begin{abstract}
Abstrak
Klasifikasi pada jenis objek sudah banyak dilakukan pada beberapa jenis data citra. Klasifikasi jenis hewan telah dilakukan menggunakan pendekatan segmentasi dan tanpa segmentasi sebagai tahapan awal. Context Aware Saliency (CAS) merupakan metode yang maтри membuat wilayah objek menjadi lebih dominan dibandingkan dengan background dalam mode saliency sehingga dapat menjadi alternative pengganti proses segmentasi objek. Fitur bentuk diambil berdasarkan citra hasil saliency menggunakan metode Histogram of Oriented Gradient (HOG). Metode K-Nearest Neighbors (K-NN) digunakan untuk klasifikasi jenis hewan mamalia berdasarkan fitur HOG dari citra saliency. Data set yang digunakan pada penelitian ini adalah LHI-Animal-Faces. Hasil yang didapatkan menunjukkan bahwa jenis hewan yang dapat dikenali dengan baik, yaitu Kucing dan Harimau, sedangkan Domba, Anjing, dan Babi belum mampu dikenali dengan baik.
\end{abstract}

Kata kunci-Context Aware Saliency, Histogram of Oriented Gradient, K-Nearest Neighbors, Mamalia, Klasifikasi

\begin{abstract}
Object classification has been done to various images. Animal classification has been done using segmentation and non-segmentation approach as initial stage. Context Aware Saliency (CAS) is a method that able to make the object area more dominant than the background in saliency mode so that it can be an alternative object segmentation process. The shape feature will taken based on saliency results using the Histogram of Oriented Gradient (HOG). The K-Nearest Neighbors (K-NN) used to classify mammal species based on HOG features from saliency images. The dataset used in this study is LHI-Animal-Faces. The results obtained show that animal species that can be recognized well are cats and tigers, while sheep, dogs, and pigs have not been able to be recognized properly.
\end{abstract}

Keywords - Context Aware Saliency, Histogram of Oriented Gradient, K-Nearest Neighbors, Mammals, Classification

\section{PENDAHULUAN}

$\mathrm{M}$ amalia merupakan hewan menyusui yang memiliki rambut di tubuhnya. Pada umumnya, mamalia merupakan hewan bertulangbelakang dan memiliki ciri-ciri seperti bernapas dengan paru-paru, berdarah panas, dan memiliki system pencernaan yang lengkap. Mamalia berkembangbiak dengan cara melahirkan namun ada juga mamalia yang berkembang biak dengan cara bertelur. Terlalu banyak perbedaan pada cirinya, membuat sulitnya membedakan jenis mamalia. 
Hewan juga dapat diidentifikasi menggunakan citra jejak kaki. Beberapa fitur yang terkandung dalam citra jejak kaki hewan dapat digunakan untuk membantu dalam identifikasi hewan. Jumlah dan ukuran gumpalan pada citra jejak kaki hewan dapat menjadi fitur untuk klasifikasi jenis hewan. Perhitungan distance dari rata-rata connected component pada setiap fitur telah dilakukan untuk klasifikasi jenis hewan berdasarkan citra jejak kaki [1]. Di sisi lain, klasifikasi jenis hewan juga sudah dilakukan oleh [2] khususnya untuk jenis hewan laut menggunakan Convolutional Neural Network (CNN) dengan seleksi fitur modifikasi minimalredundancy-maximal relevance (mRMR) pada citra wajah hewan.

Citra wajah hewan sendiri menjadi tantangan sebagai data untuk proses klasifikasi jenis hewan. Pada penelitian [3], klasifikasi jenis hewan juga telah dilakukan menggunakan algoritma maximal region merging untuk segmentasinya dan Gabor sebagai fiturnya. Tidak hanya itu, klasifikasi jenis hewan yang menggunakan proses segmentasi juga telah dilakukan oleh [4]. Pada penelitian [4] telah dilakukan klasifikasi jenis hewan menggunakan tahap segmentasi terlebih dahulu. Segmentasi dilakukan menggunakan metode Graph Cut untuk menghilangkan background dari objek hewan. Kemudian hasil segmentasi citra hewan tersebut dipartisi dalam sejumlah blok dan selanjutnya dilakukan ekstraksi fitur warna dan tekstur pada setiap blok. Hasil ekstraksi fitur tersebut digunakan untuk proses klasifikasi menggunakan Probabilistic Neural Network (PNN) dan K-Nearest Neighbors (K-NN) pada 25 jenis hewan. Hasil penelitian menunjukkan bahwa klasifikasi menggunakan metode K-NN memiliki akurasi yang lebih baik dibandingkan dengan PNN.

Klasifikasi yang tidak melibatkan proses segmentasi juga telah dilakukan oleh [5]. Pada penelitian [5] dilakukan perbandingan fitur lokal meliputi Histogram of Oriented Gradient (HOG), Local Binary Pattern (LBP), dan Fourier-LBP terhadap metode klasifikasi Support Vector Machine (SVM). Tidak hanya itu, perbandingan juga dilakukan dengan menggunakan CNN. Pada penelitiannya [5], didapatkan bahwa fitur HOG lebih baik dibandingkan dengan fitur lokal lainnya untuk klasifikasi SVM.

Context Aware Saliency (CAS) merupakan metode yang digunakan untuk mendeteksi objek. Metode ini dapat memisahkan objek dengan background. Metode CAS merupakan metode yang bekerja berdasarkan intensitas pixel dalam citra. Secara visual penyebaran pixel pada background berbeda dengan objek. Perbedaan penyebaran pixel ini kemudian dipetakan ke dalam mode saliency [6]. CAS merupakan alternatif lain untuk memisahkan objek dengan background layaknya segmentasi objek. Dengan menggunakan CAS maka wilayah objek menjadi lebih dominan dibandingkan dengan background. Hal ini akan digunakan dalam penelitian agar bentuk objek lebih terlihat.

Metode HOGakan digunakan untuk mengambil fitur bentuk dari citra dalam mode saliency berupa histogram. Berdasarkan hal tersebut, maka akan dilakukan klasifikasi wajah hewan mamalia menggunakan ekstraksi fitur CAS dan HOG dengan K-NN classifier.

\section{METODE PENELITIAN}

Dalam penelitian ini data yang digunakan diperoleh dari public dataset. Dataset yang digunakan adalah LHI-Animal-Faces yang terdiri dari 21 jenis citra wajah hewan tampak depan [7]. Dataset tersebut disesuaikan dengan kebutuhan penelitian ini sehingga diambil 15 jenis hewan yang merupakan jenis hewan mamalia. Masing-masing jenis hewan mamalia terdiri dari 60 citra dengan ukuran 150x150 pixel. Adapun citra hewan mamalia pada dataset LHI-AnimalFaces dapat dilihat pada Gambar 1. 


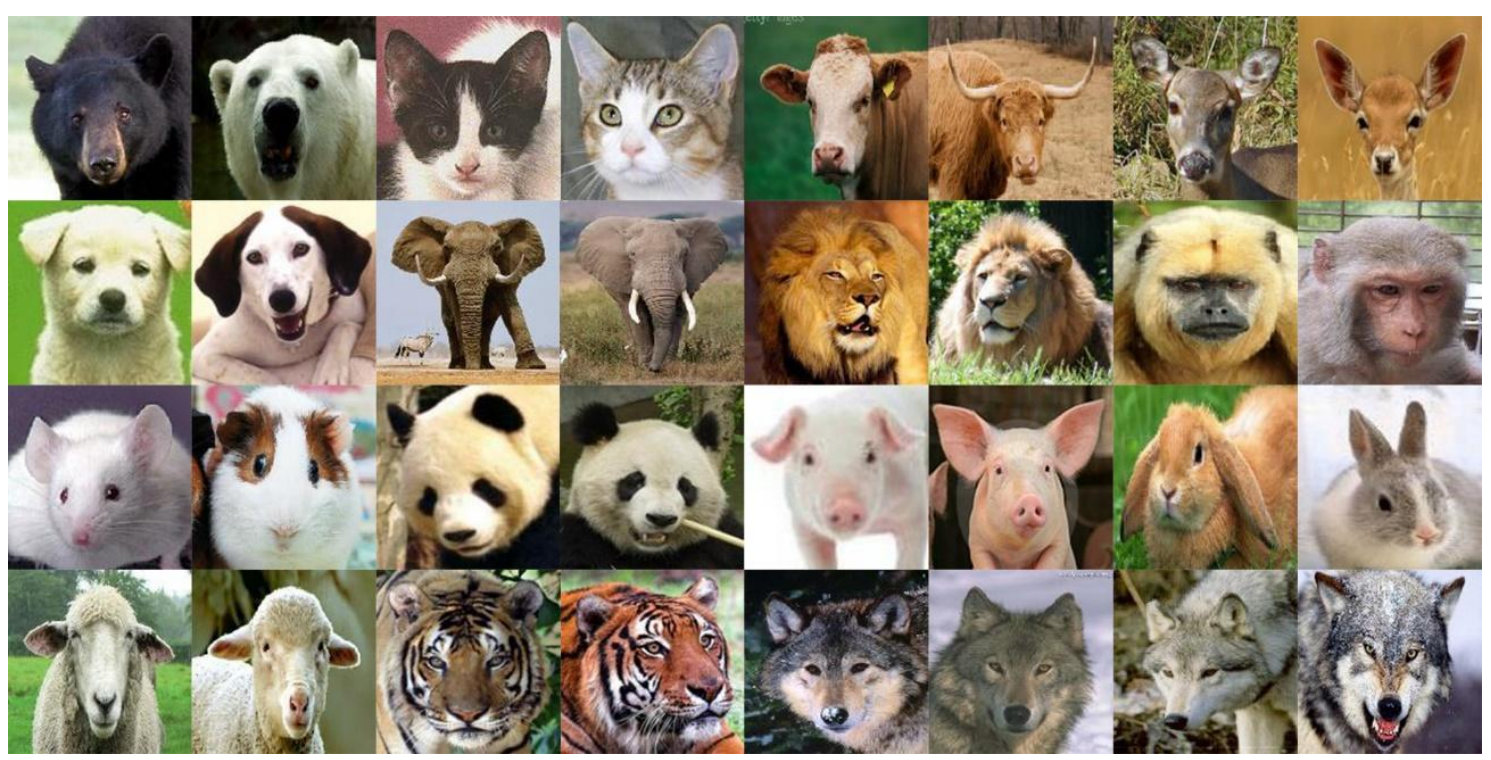

Gambar 1. Beberapa Wajah Hewan Mamalia pada Dataset LHI-Animal-Faces [7]

Dalam penelitian yang dilakukan, ada beberapa tahapan yang dilakukan. Tahapan tersebut, yaitu membagi dataset menjadi data uji dan data latih. Data latih menggunakan 50 citra pada setiap jenis hewan mamalia, sedangkan data uji menggunakan 10 citra pada setiap jenis hewan mamalia. Data latih kemudian dilakukan ekstraksi fitur menggunakan CAS. Setelah diekstraksi menggunakan fitur CAS tersebut kemudian diekstraksi lagi menggunakan HOG. Fitur akhir hasil ekstraksi disimpan pada database. Sama seperti data latih, data uji juga diperlakukan sama. Data uji diekstraksi fitur menggunakan CAS dilanjutkan dengan HOG. Metode klasifikasi yang digunakan yaitu K-NN. K-NN digunakan untuk menghitung jarak antara fitur data uji dengan fitur data latih. K-NN menghasilkan urutan dari jarak terkecil sampai terbesar. Jarak terkecil menunjukkan kemiripan antara data uji dan data latih. Secara keseluruhan, metode yang diusulkan dapat dilihat pada Gambar 2.

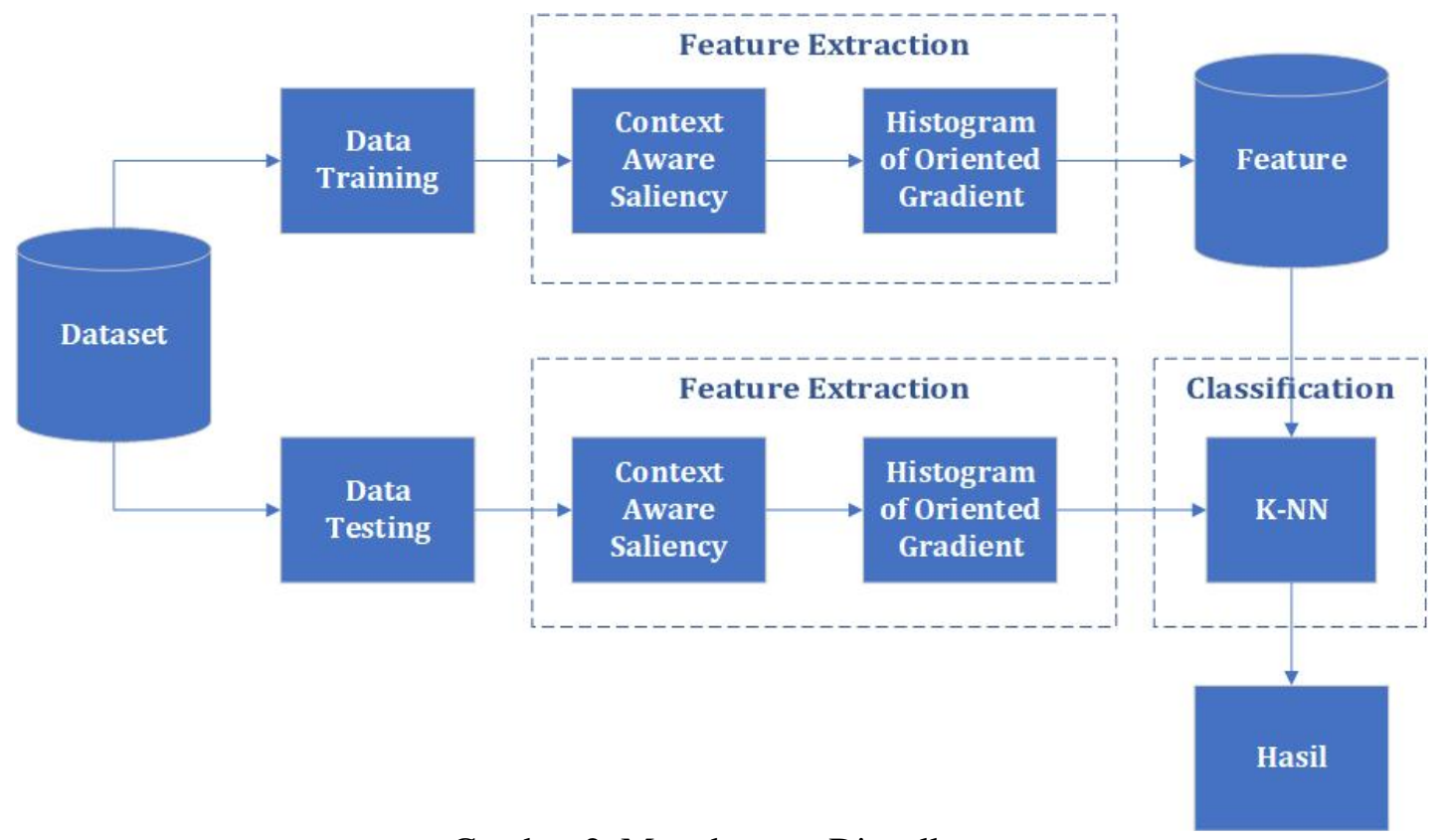

Gambar 2. Metode yang Diusulkan 


\subsection{Context Aware Saliency (CAS)}

Langkah-langkah metode CAS adalah sebagai berikut [6]:

1. Membagi image ke dalam patch.

2. Menghitung kesamaan warna untuk masing-masing patch.

3. Menghitung jarak untuk masing-masing patch.

4. Menghitung dissimillarity antar patch.

5. Menentukan nilai saliency.

\section{2 Histogram of Oriented Gradient ( $H O G)$}

Langkah-langkah metode HOG adalah sebagai berikut [8]:

1. Melakukan normalisasi warna pada citra.

2. Menghitung gradiencitra.

3. Melakukan spatial dan orientation binning.

4. Melakukan normalisasi dan membentuk descriptor block.

\section{2. $3 K$-Nearest Neighbor ( $K$-NN)}

Langkah-langkah metode K-NN adalah sebagai berikut [9]:

1. Menentukan nilai $\mathrm{K}$ yang akan digunakan.

2. Menghitung Euclidean Distance untuk masing-masing data uji terhadap data latih.

3. Mengurutkan distance yang didapatkan secara ascending.

4. Memilih $\mathrm{K}$ teratas pada hasil distance yang telah diurutkan.

5. Menetapkan label berdasarkan mayoritas K.

\section{HASIL DAN PEMBAHASAN}

Hasil ekstraksi fitur yang digunakan untuk klasifikasi dapat dilihat pada Gambar 3. Citra asli jenis hewan mamalia diekstraksi menggunakan CAS sehingga menghasilkan citra saliency. Selanjutnya, HOG digunakan untuk mengambil fitur bentuk dari citra saliency.

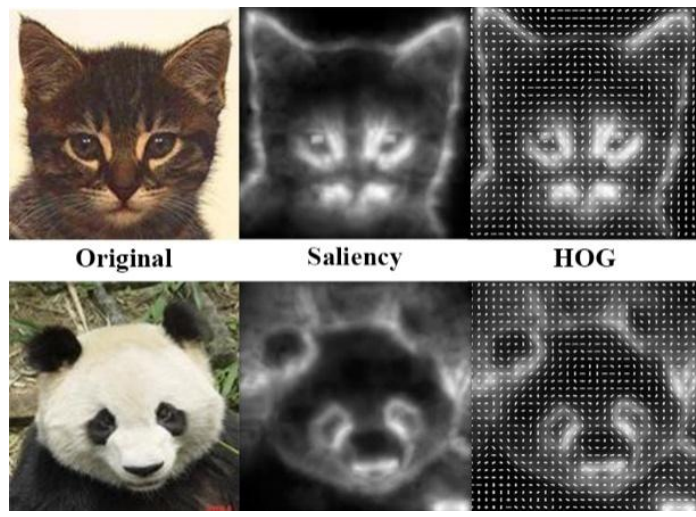

Gambar 3. Visualisasi Ektraksi Fitur

Hasil klasifikasi menunjukkan kemampuan K-NN untuk mengenali objek bervariasi. Ada objek yang dapat diklasifikasi dengan baik namun ada pula yang tidak dapat diklasifikasi dengan baik.Hasil klasifikasi dengan menggunakan $\mathrm{k}=3$ dapat dilihat pada Tabel 1. Berdasarkan Tabel 1 dapat dilihat Kucing dan Sapi dapat dikenali sebanyak 90\%. Sebaliknya, Domba merupakan hewan yang dikenali sebanyak $10 \%$. 
Tabel 1. Hasil Klasifikasi dengan $\mathrm{k}=3$

\begin{tabular}{|c|l|c|c|c|}
\hline No. & Jenis & Jumlah Data & Benar & Akurasi \\
\hline 1 & Beruang & 10 & 7 & $70 \%$ \\
\hline 2 & Kucing & 10 & 9 & $90 \%$ \\
\hline 3 & Sapi & 10 & 9 & $90 \%$ \\
\hline 4 & Rusa & 10 & 7 & $70 \%$ \\
\hline 5 & Anjing & 10 & 4 & $40 \%$ \\
\hline 6 & Gajah & 10 & 5 & $50 \%$ \\
\hline 7 & Singa & 10 & 5 & $50 \%$ \\
\hline 8 & Monyet & 10 & 6 & $60 \%$ \\
\hline 9 & Tikus & 10 & 6 & $60 \%$ \\
\hline 10 & Panda & 10 & 6 & $60 \%$ \\
\hline 11 & Babi & 10 & 2 & $20 \%$ \\
\hline 12 & Kelinci & 10 & 3 & $30 \%$ \\
\hline 13 & Domba & 10 & 1 & $10 \%$ \\
\hline 14 & Harimau & 10 & 8 & $80 \%$ \\
\hline 15 & Serigala & 10 & 7 & $70 \%$ \\
\hline
\end{tabular}

Sedangkan hasil klasifikasi dengan menggunakan k=5 dapat dilihat pada Tabel 2. Berdasarkan Tabel 2 dapat dilihat Kucing dan Harimau memiliki akurasi mencapai $100 \%$. Namun Babi memiliki akurasi mencapai $10 \%$.

Tabel 2. Hasil Klasifikasi dengan $\mathrm{k}=5$

\begin{tabular}{|c|l|c|c|c|}
\hline No. & Jenis & Jumlah Data & Benar & Akurasi \\
\hline 1 & Beruang & 10 & 4 & $40 \%$ \\
\hline 2 & Kucing & 10 & 10 & $100 \%$ \\
\hline 3 & Sapi & 10 & 7 & $70 \%$ \\
\hline 4 & Rusa & 10 & 6 & $60 \%$ \\
\hline 5 & Anjing & 10 & 2 & $20 \%$ \\
\hline 6 & Gajah & 10 & 6 & $60 \%$ \\
\hline 7 & Singa & 10 & 6 & $60 \%$ \\
\hline 8 & Monyet & 10 & 5 & $50 \%$ \\
\hline 9 & Tikus & 10 & 4 & $40 \%$ \\
\hline 10 & Panda & 10 & 6 & $60 \%$ \\
\hline 11 & Babi & 10 & 1 & $10 \%$ \\
\hline 12 & Kelinci & 10 & 3 & $30 \%$ \\
\hline 13 & Domba & 10 & 2 & $20 \%$ \\
\hline 14 & Harimau & 10 & 10 & $100 \%$ \\
\hline 15 & Serigala & 10 & 8 & $80 \%$ \\
\hline
\end{tabular}

Sedangkan hasil klasifikasi dengan menggunakan k=7 dapat dilihat pada Tabel 3 . Berdasarkan Tabel 3, Kucing dan Harimau memiliki akurasi 90\%. Namun Anjing memiliki akurasi $10 \%$.

Tabel 3. Hasil Klasifikasi dengan $\mathrm{k}=7$

\begin{tabular}{|c|l|c|c|c|}
\hline No. & Jenis & Jumlah Data & Benar & Akurasi \\
\hline 1 & Beruang & 10 & 4 & $40 \%$ \\
\hline 2 & Kucing & 10 & 9 & $90 \%$ \\
\hline 3 & Sapi & 10 & 7 & $70 \%$ \\
\hline
\end{tabular}




\begin{tabular}{|c|l|c|c|c|}
\hline 4 & Rusa & 10 & 6 & $60 \%$ \\
\hline 5 & Anjing & 10 & 1 & $10 \%$ \\
\hline 6 & Gajah & 10 & 8 & $80 \%$ \\
\hline 7 & Singa & 10 & 5 & $50 \%$ \\
\hline 8 & Monyet & 10 & 5 & $50 \%$ \\
\hline 9 & Tikus & 10 & 3 & $30 \%$ \\
\hline 10 & Panda & 10 & 7 & $70 \%$ \\
\hline 11 & Babi & 10 & 2 & $20 \%$ \\
\hline 12 & Kelinci & 10 & 3 & $30 \%$ \\
\hline 13 & Domba & 10 & 2 & $20 \%$ \\
\hline 14 & Harimau & 10 & 9 & $90 \%$ \\
\hline 15 & Serigala & 10 & 8 & $80 \%$ \\
\hline
\end{tabular}

Sedangkan hasil klasifikasi dengan menggunakan k=9 dapat dilihat pada Tabel 4 . Berdasarkan Tabel 4 dapat dilihat Kucing dan Harimau memiliki akurasi mencapai $100 \%$. Namun Babi memiliki akurasi mencapai 10\%.

Tabel 4. Hasil Klasifikasi dengan $\mathrm{k}=9$

\begin{tabular}{|c|l|c|c|c|}
\hline No. & Jenis & Jumlah Data & Benar & Akurasi \\
\hline 1 & Beruang & 10 & 4 & $40 \%$ \\
\hline 2 & Kucing & 10 & 6 & $100 \%$ \\
\hline 3 & Sapi & 10 & 6 & $70 \%$ \\
\hline 4 & Rusa & 10 & 6 & $60 \%$ \\
\hline 5 & Anjing & 10 & 2 & $20 \%$ \\
\hline 6 & Gajah & 10 & 6 & $60 \%$ \\
\hline 7 & Singa & 10 & 5 & $60 \%$ \\
\hline 8 & Monyet & 10 & 5 & $50 \%$ \\
\hline 9 & Tikus & 10 & 3 & $40 \%$ \\
\hline 10 & Panda & 10 & 6 & $60 \%$ \\
\hline 11 & Babi & 10 & 1 & $10 \%$ \\
\hline 12 & Kelinci & 10 & 4 & $30 \%$ \\
\hline 13 & Domba & 10 & 3 & $20 \%$ \\
\hline 14 & Harimau & 10 & 9 & $100 \%$ \\
\hline 15 & Serigala & 10 & 9 & $80 \%$ \\
\hline
\end{tabular}

Setiap data pada tabel kemudian digabungkan untuk menghasilkan perbandingan jumlah objek yang dapat dikenali terhadap nilai k. Perbandingan jumlah objek yang dikenali terhadap nilai k dapat dilihat Gambar 4. 


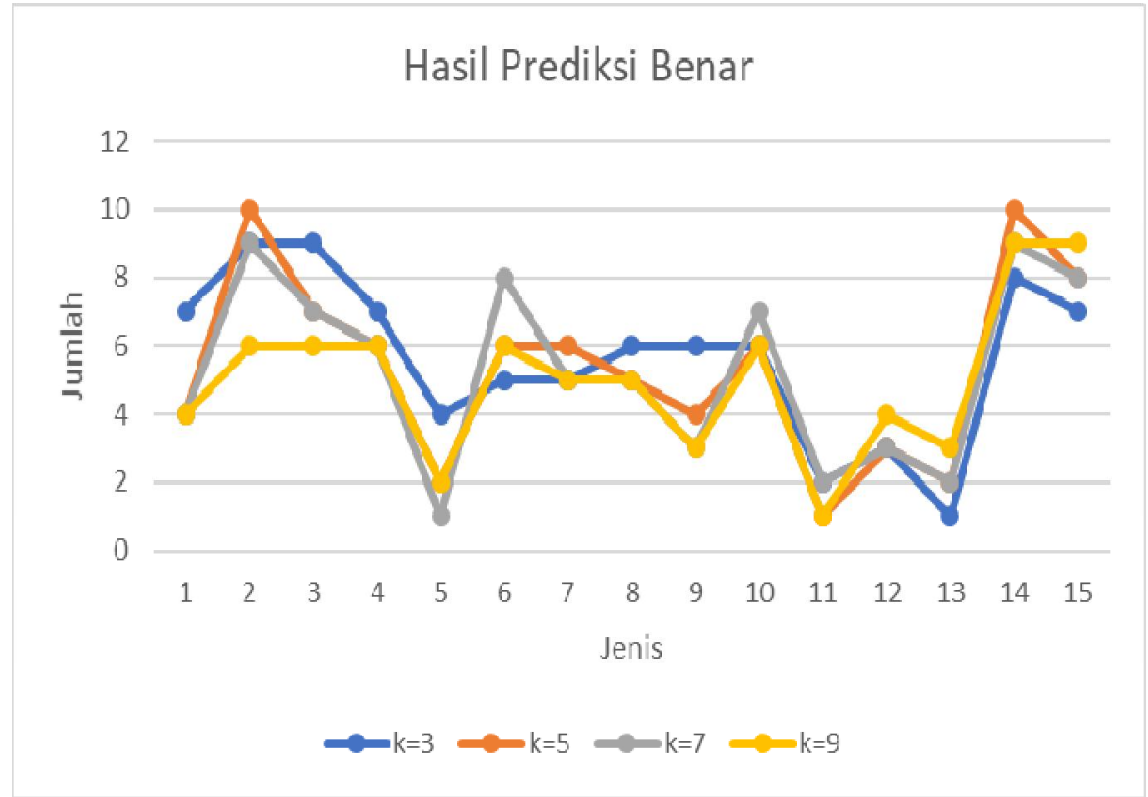

Gambar 4. Perbandingan Hasil Prediksi Benar Terhadap Nilai k.

Berdasarkan Gambar 2, nilai k mempengaruhi hasil klasifikasi untuk masing-masing jenis hewan. Peningkatan nilai $\mathrm{k}$ dapat meningkatkan atau menurunkan bahkan tidak ada perubahan hasil prediksi. Nilai $\mathrm{k}$ yang memberikan hasil klasifikasi yang terbaik yaitu $\mathrm{k}=5$ yang terlihat ada jenis hewan yang dapat dikenali $100 \%$.

\section{KESIMPULAN}

Berdasarkan hasil penelitian ini dapat disimpulkan nilai $\mathrm{k}$ dapat memberikan hasil klasifikasi yang berbeda-beda. Nilai k yang memberikan hasil klasifikasi yang baik yaitu $\mathrm{k}=5$. Hewan yang dapat dikenali dengan baik yaitu Kucing dan Harimau. Hewan yang tidak dapat dikenali dengan baik yaitu Domba, Anjing dan Babi. Hewan yang lain masih dapat dikenali namun tidak seperti Kucing dan Harimau. Fitur CAS dan HOG mampu mendapatkan fitur dari Kucing dan Harimau namun tidak efektif untuk Domba, Anjing dan Babi.

\section{DAFTAR PUSTAKA}

[1] M. N. Alli and S. Viriri, "Animal Identification Based On Footprint Recognition," IEEE Int. Conf. Adapt. Sci. Technol. ICAST, 2013.

[2] Z. Cao, J. C. Principe, B. Ouyang, F. Dalgleish, and A. Vuorenkoski, "Marine Animal Classification Using Combined CNN and Hand-Designed Image Features," Ocean. 2015 - MTS/IEEE Washingt., pp. 2-7, 2015.

[3] N. Manohar, Y. H. S. Kumar, and G. H. Kumar, "Supervised and Unsupervised Learning in Animal Classification," 2016 Int. Conf. Adv. Comput. Commun. Informatics, ICACCI 2016, pp. 156-161, 2016.

[4] Y. H. S. Kumar, N. Manohar, and H. K. Chethan, "Animal Classification System: A Block Based Approach," Procedia Comput. Sci., Vol. 45, No. C, pp. 336-343, 2015. 
[5] S. Taheri and Ö. Toygar, "Animal Classification Using Facial Images with Score-Level Fusion," IET Comput. Vis., Vol. 12, No. 5, pp. 679-685, 2018.

[6] S. Goferman, L. Zelnik-Manor, and A. Tal, "Context-Aware Saliency Detection," IEEE Trans. Pattern Anal. Mach. Intell., Vol. 34, No. 10, pp. 1915-1926, Oct. 2012.

[7] Z. Si and S. Zhu, "Learning Hybrid Image Templates (HIT) by Information Projection," IEEE Trans. Pattern Anal. Mach. Intell., pp. 1354-1367, 2012.

[8] N. Dalal and B. Triggs, "Histograms of Oriented Gradients for Human Detection," in Proceedings 2005 IEEE Computer Society Conference on Computer Vision and Pattern Recognition, CVPR 2005, 2005, Vol. I, pp. 886-893.

[9] J. P. Jose, P. Poornima, and K. M. Kumar, "A Novel Method for Color Face Recognition Using KNN Classifier,” 2012 Int. Conf. Comput. Commun. Appl. ICCCA 2012, 2012. 